\title{
AN EXPLORATORY STUDY OF THE PROBLEMS FACED BY THE DISTRICT TEACHER EDUCATORS (DTES) REGARDING THEIR PROFESSIONAL EXPERIENCES IN PRIMARY SCHOOLS OF PUNJAB
}

\author{
Nasrin Akhter* \\ Khalid Saleem ${ }^{*}$ \\ Farhana Kausar Awan ${ }^{* *}$
}

\begin{abstract}
In an attempt to enhance educational quality, the Province of the Punjab introduced District Teachers Educators (DTE) into schools (mainly primary) with the aims of offering support and mentoring to teachers, providing professional development opportunities along with a monitoring role based mainly on monthly student- testing. The main objective of this study is to explore the problems the DTE face in fulfilling their roles in schools. A sample was selected by using convenient sampling technique. The qualitative approach was used to collect data through interviews in this study. This study reveals problems related to the ownership of the process by teachers and head-teachers, the lack of resources often hindering effective work, and the entire process of monitoring by means of student testing facing great difficulties. The conflict in the roles of the DTE is discussed as they seek to integrate a supportive role with that of monitoring, whereas the basis of monitoring is questioned in the light of consistent international research evidence. The study recommends that the conflicts among the monitoring teachers should be resolved. Moreover, their time would be better spent in the supportive-enhancement role, leaving the monitoring role aside. It is suggested that DTEs should be given time to read, and collate evidence from the wide range of literature to learn new insights in education.
\end{abstract}

Keywords: District Teachers Educators, Professional Development, Mentoring, Monitoring, High-stakes testing

\footnotetext{
* Assistant Professor of Education, University of Education, Lahore

** PhD Education Scholar, University of Punjab, Lahore
} 


\section{Introduction}

In primary stages of education in Pakistan, District Teacher Educators were appointed some years ago in the province of Punjab. Their task is to work with teachers in schools, organized in clusters by locality, with remits for three somewhat conflicting roles:

(a) A supportive and mentoring role by which they offer professional development days, liaise with head-teachers, and encourage the implementation of teacher guides, teacher diaries and lesson plans.

(b) Oversee monthly assessment of student performance in tests designed for the purpose, feeding back findings to the schools.

(c) Maintaining data relating to schools, teachers, and students, with the preparation of appropriate reports.

It is very clear that professional training for teachers with ongoing professional development is very important (OECD, 2005; Harris, 2001). Part of the way the District Teacher Educators operate in the Punjab relates to the way schools are clustered for support. The aim here is to harness professional exchange and sharing among teachers. There is an added bonus: it brings training and support right into the schools rather than taking teachers out for training. The system is governed by the Guidebook for District Teacher Educators (2010).

With several years experience of the system, the time was ripe to explore the perceptions of the District Teacher Educators about different problems which they face in undertaking their roles. Is the system working? What issues have they faced? Specifically, what problems have they encountered in the assessment of the students and teachers at schools, mentoring of teachers at schools, the professional development days and head teachers meetings at their schools.

\section{Review of the Background Literature}

Professional development has been described in different ways. Joyce et al. (1976) speaks in terms of the goal being to generate improvement and relate this to the development of people, their skills and competence while Gall and Renchler (1985) talk about improving the capacity of teachers 'to function as effective professionals (6)'.

Fullan (1995: 265) set this in the context of a learning environment 'under conditions of complexity and dynamic change' while Day and Sachs (1999:27) also emphasize the context of change and stress the 
ongoing nature of the development. The overall goals seek to bring benefits to:

- Teachers and their professional skills;

- Groups of teacher in their collaboration;

- Schools as learning communities.

In looking at how professional development is made available, Gaible and Burns (2005:25) divided teacher professional development into three broad categories:

(1) Centralised approach: most often using lectures and workshops with large glories of teachers.

(2) Group approach: Smaller groups of teachers, often from the same subject area, often focusing on specific situational problems.

(3) Independent learning: Sometimes initiated by teachers individually, using available resources that may include computers and internet.

The advantages of the first approach lie in the way large numbers can be involved simultaneously, sharing the same experiences, giving economies of time and leadership resources. However, such development often fails to address local issues and requires considerable organization. Here, the group approach can address more localized issues and give opportunities for genuine interactions between the teachers as well as with the person leading the development. Pelgrum and Law (2003) stress the value of focusing on a single set of teachers with shared issues. Neither the centralized nor the group approach really address the idiosyncratic needs of individual teachers nor do they take into account the timing of these needs. Various authors (Feiman-Nemser, 2001; Hammerness et al., 2005) emphasize that different teachers have different requirements. Too often, teachers come away from professional development experiences with dissatisfaction that their specific needs have not been addressed. Sometimes, these are very precise: related to handling specific needs in learners, specific topics and themes in the curriculum, specific assessment needs, and learner motivation, etc.

Various writers (Hammerness, 2005) focus on personal identity formation as a critical factor in defining professional learning needs of experienced teachers. This appreciates the specific needs of teachers and the diverse contexts of the needs (as practitioners, as change agents, as nurturers and child advocates, as moral agents). Hammerness et al. (2005) argue that professional learning is not a linear process and cannot rely on predictable stages of teacher development in order to design 
professional development. It is essential to consider context, unique personal needs or even individual development.

One of the key roles of the District Teachers Educators relates to the support and mentoring of primary teachers in areas of the latest teaching technologies as well as offering guidance and support in enhancing teaching skills, identifying needs and seeking to offer appropriate support. Training courses are developed as needed (Guidebook for DTEs, 2010). Many authors have discussed the important role of mentoring (Kolb, 1984; Akker, 1998; Voogt, 1993; Batesko, 2011) with Susan and Catherine (2006) suggesting that the role of mentoring in professional development is highly advantageous for both mentor and mentee. The problem is that different teachers may have widely differing attitudes to the offer of mentoring, whereas the role of the District Teachers Educators in assessing students conflicts with the supportive role.

In some ways, the District Teachers Educators have an almost impossible role. On one hand, they are there to offer support and training. On the other hand, they monitor what is going on by gathering test data. Many teachers may resent the latter, others may be unwilling to develop fully trusted relationships in this context (University of Education, 2015), while others may feel under peer pressures. Bowe (2005) notes the personal insecurities of many teachers in a mentoring situation. This may include a feeling of gross overwork, resentment against the disturbance of school activities, and a lack of trust generated by the conflicting roles of District Teachers Educators in terms of support as well as monitoring of test data. There are suggestions that may lead teachers to employ all kinds of inappropriate tactics which includes falsifying test data and blackmailing mentors.

District Teachers Educators have to work with head-teachers and this is another area open to difficulties. Head-teachers carry many responsibilities, and often have to work within inadequate buildings and teaching facilities and resources. Working with District Teachers Educators is another burden to be faced by pressurized head-teachers. Regarding the relationship between head teachers and students, Blair and Bourne (1998) and Fletcher and Burnderett (2005) emphasize good relationships, while Lewis and Murphy (2008) focus on the head teachers generating a school culture. In considering head-teachers and school teachers, the fundamental problems with District Teachers Educators can arise because 'outsiders' are, from their point of view, imposed on the schools and they are not convinced of the benefits such people can bring. 
The objectives of this study can be seen in investigating the nature of any problem relating to four areas (see figure 1)

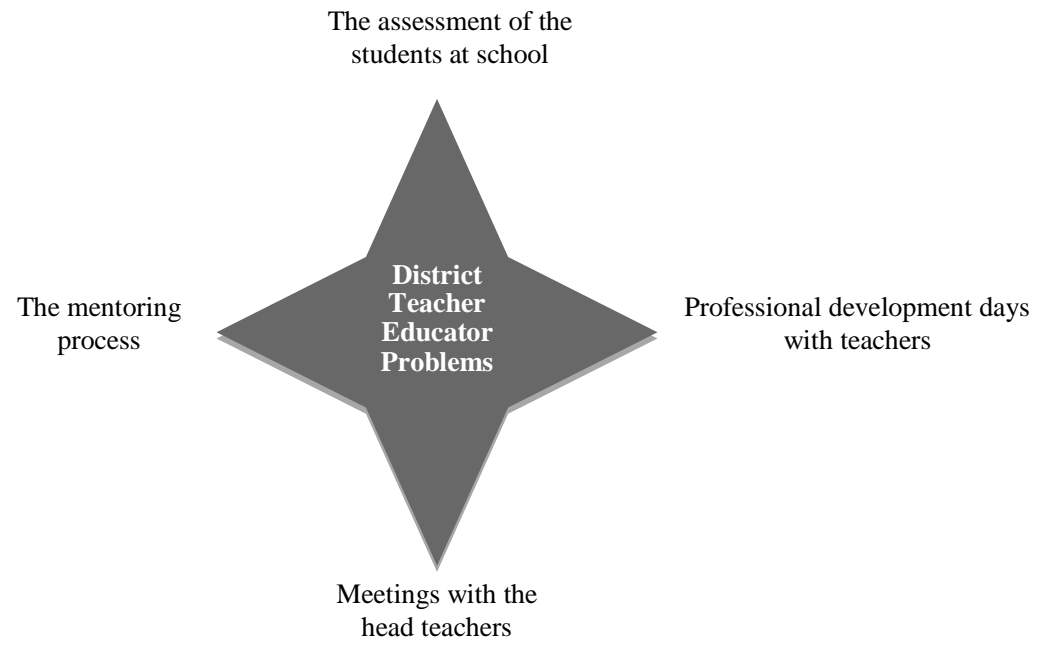

Figure 1. Study Objectives

The key issues being explored relate to an identification of the exact nature of the problems the four areas as shown in figure 1, seeking pointers towards possible ways forward. Identification of the origin and detail of the problems in each of the four areas is a first step. This may assist in moving towards ways by which the problems can be minimized.

\section{Methodology}

\section{Research Design}

Qualitative research simply requires a broader and less restrictive concept than the quantitative research. Thus, Becker, Geer, Hughes, and Strauss (1961), "we can say what this was by describing our original view of the problem, our theoretical and methodological commitments, and the way these affected our research and were affected by it as we proceeded" (p. 17). This research used the qualitative approaches in the context of exploring the difficulties encountered by the DTEs in their primary schools. For this, different questions (open ended in nature) to the DTEs were asked regarding their duties and their problems they faced as District Teachers Educators. A semi structure interview schedule was developed for District Teachers Educators to find out their 
problems about the assessment, mentoring, and meeting with head teachers and professional development days. The interview questions were formulated in the light of the stated roles and duties of the DTEs.

\section{Participants}

A sample of 64 out of 82 DTEs was selected from the primary schools. The characteristics of the DTEs are that they are currently teaching different courses at primary schools. These DTEs are in different age groups between 30 and 45 . To be appointed as a DTE, the school teachers should have at least three years full time teaching experience, be qualified at B.Ed, BA or, preferably, MA level. Therefore, the majority of the teachers were post-graduates with MA, MEd and some also possess M.Phil degree. Moreover, majority of the DTEs have more than 5 years of teaching experience. Questions in the structured questionnaire and interviews focused around how the DTEs perceived the problems related to the duties laid down for their roles of District Teachers Educators.

\section{Instruments}

To explore the problems in the four areas shown in figure 1, the open-ended questionnaires and semi-structured interviews were conducted with District Teachers Educators. An open-ended questionnaire to explore the problems of District Teachers Educators towards assessment, mentoring, meeting with heads and professional development day was also used. In this study, two qualitative methods were combined to better answer the research questions. Thus, there are advantages in conducting qualitative research to meet the aims of the study to explore the DTEs difficulties. Hence, an exploratory qualitative approach can be the best to seek the issues in a depth through which the issues and difficulties were explored meaningfully. Therefore, the data gathered were analyzed qualitatively with problems of DTEs related to:

- Daily visit to the schools in a cluster

- Monthly assessment of students in schools

- Maintenance of data regarding schools, teachers, students and preparation of CTSC (Clusstered Training School Center) file

- Organisation of professional development days

- Head teacher meetings

- Implementation of Teacher Guides, Teacher Diaries, Lesson Plans

- Mentoring and professional development of school staff 


\section{Data Collection}

The validity of the interview guide was checked by matching the issues raised to the roles laid down for District Teachers Educators as well as discussing the wording with colleagues. As a pilot, eight questionnaires (open ended items) were delivered to the DTEs and three interviews were undertaken with the DTEs, followed by the discussion. In all this, there was an opportunity to check if the wording was understood as intended and the main issues were being addressed.

Usually, the researcher themselves went to the primary schools or to the offices of the DTEs; the open ended questionnaires were completed in the researchers' presence although a few had to be emailed out. Indeed, the two methods have been used. Open-ended questionnaire and semistructured interviews. Both generated qualitative data. The open ended questionnaires generated qualitative data too. Overall 42 of the total 49 open-ended questionnaires were received. Likewise, the researchers themselves visited the primary schools and all interviews from DTEs were recorded. It was noticed that male DTEs were extremely willing to take part in interviews but only two females DTEs agreed to be interviewed. Audiotapes were used to transcribe the interviews.

\section{Results}

Interview transcripts and questionnaire scripts were read through to identify the key themes raised by participants. The key themes were coded and then a second reading looked for any further information offered. Being very brief, the interview data was succinct and focused. The interview and questionnaire were designed to reflect the four themes shown in figure 1; the sub-themes were grouped under each of these themes.

The findings under each of the four areas of difficulty are now discussed in turn.

\section{(1) The Assessment of the Students}

The following issues were observed in the data:

\section{(a) Unfair means}

This was the phrase used by half of the respondents and it describes all kind of tactics employed to enable students to gain higher grades. Students were sometimes pressurized to perform better by means of 
encouraging copying and cheating as well as giving inappropriate assistance. Unfair means was a big challenge:

They adopt strict behavior with the DTEs as well as they pressurize the students to use unfair means such as copying, cheating and helping the students who are weak in the subjects in whom they are assessed [R9].

Another said,

I have made many improvements in assessment system but I have not succeeded in controlling the use of unfair means [R11].

\section{(b) Non- cooperative behaviour from male teachers}

Quite a few of the District Teachers Educators reported that male teachers often tended to be less cooperative: They always remain in search of excuses to avoid this process.[R5] Clearly the men tended to resent the testing process.

\section{(c) Misuse of friendly environment}

It is a difficult issue for District Teachers Educators to know the extent to which they should follow strict practices and where a more relaxed atmosphere was appropriate, especially in relation to the testing.

In general, they argued for following rules and procedures:

They misuse their relaxation and demand favour for assessment. And this is exploitation for those who work hard and prepare their students for assessment. [R7]

They also added that sometimes teachers create problems due to friendly environment.

\section{(d) Teacher interference}

Most of the District Teachers Educators said that the teachers interfere in the process and try to help the students to solve questions:

They are always of the opinion that assessment is wastage of time and it has no effect on the students as well as the teachers' performance. So they think that assessment process should not be included. [R14]

\section{(e) Absence of training}

The majority of the District Teachers Educators saw themselves as facing difficulties in the analysis, interpretation and onward transmission of the results to the school:

Their training regarding assessment is missing. That is way DTEs are unable to bring betterment in the teaching learning process as well as conveying the result of assessment well in time. [R2] 


\section{(f) Mismanagement in distribution of papers}

Most of the District Teachers Educators stated that the papers are mostly provided for them at the very last minute, leading to difficulties in printing and photo copying:

They do not have time for proof reading of the paper. In this situation they have to face the miss printing in photo copies and in time distribution remains tough for them. [R9]

\section{(g) Delay in results}

Half of the District Teachers Educators stated that work load prevented them conveying the results of the assessment in good time:

Females have to face more problems than males to submit results in time due to transportation and results are not dispatched at proper time. [R6]

It was noticeable that the urban schools submitted the results in time while rural schools were often delayed due to travel distances.

\section{(h) Lack of motivation}

A majority of District Teachers Educators commented that experienced teachers have little motivation. Thus:

Newly recruited educators are more energetic and having fresh and latest knowledge. Therefore assessment results show no improvements in the teaching competency of experienced teachers. [R1]

A few of the District Teachers Educators claimed that the experienced teachers seemed to have little interest in their own development or moving practices forward:

Old teachers have no spirit of competition to compete for betterment of the students' education but they compete just to maintain their grades. They just want to save themselves from punishment on poor results. [R4]

\section{(i) Demand of High Ranks}

A large majority of the District Teachers Educators clearly saw competition as the way to improve test outcomes although, in fact, there is no evidence to support this (Nichols \& Berliner, 2007). They noted that schools want high rankings but did not seem to work for them:

Teachers do not work according to planner. Thus, they fail to complete the syllabus according to scheduled time. They fail to maintain the assigned duties that is why they get poor ranking. [R4] 
They saw teachers as using any strategy available to gain these performance ranks, often at the expense of the educational health of students:

After assessment, results ranking also generate the non cooperative attitude by the teachers who do not like to disturb their grades in the assessment process. [R8]. Moreover, Teachers do not plan their lesson according to the syllabus given to them. Moreover, their planning lack sequence. [R3]

The findings can be summarised (figure 2):

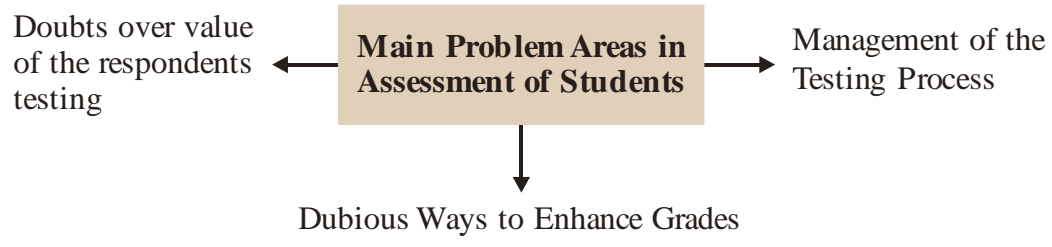

Figure 2. Assessment Issues

\section{(2) The Mentoring Process at school}

The following issues were observed in the data:

\section{(a) Non attractive environment}

The majority of the District Teachers Educators appreciated the vital importance of school environment:

Environment should be flexible for the teachers, he / she is to give every new skill, technique that is available to the world education system [R7].

Therefore, there should be internet access, experienced helpers and guidance books.

\section{(b) School politics}

Some of the District Teachers Educators stated that teacher politics also affected mentoring process:

Newly appointed educators wished to become skilled at practical life from seniors but the atmosphere was not favorable for them. Seniors are narrow minded [R2].

This is a serious issue. In a very hierarchical society, those in senior positions can easily blight the development of others, thus holding back progress considerably. 


\section{(c) Qualification}

It was noticed that the less qualified teachers had the greatest problems. One of the respondents viewed medium of English is the major problem for less qualified PSTs. The less qualified teachers were unable to understand new syllabus:

The Matric PSTs who are about to retire avoid this nerve breaking work to better their teaching. They not only face a problem of language but also face a problem of teaching material that does not match with their qualification [R9].

Therefore, they fail to follow the instructions delivered by District Teachers Educators.

\section{(d) Non supportive attitude of community}

It was felt that lack of interest by parents along with lack of community support caused the mentoring process to suffer:

The interest of parents and involvement of community can rapidly move the teachers and students to the highest level of success [R8].

\section{(e) Difficulty with the Syllabus}

Majority of the respondents indicated that many teachers cannot keep up with the rapid change in the curriculum, supposedly made to meet the challenges of global educational world

I think to improve the quality teaching, subject specialists should teach at primary grade levels. [R8]

Those trained in the decades of the 80s and 90s face huge challenges regarding incessant changes in curriculum as what is to be taught and how it is to be taught.

\section{(f) Insufficient facilities}

The majority of the District Teachers Educators noted the lack of supplementary teaching materials available at primary school level:

Primary school level students take interest in learning and feel attraction in supporting materials such as computer, multimedia etc. They learn more and more through activities rather than typical teaching system. So department should provide such facilities in primary schools and teacher should also be trained to use the computer and multimedia [R12].

Lack of facilities and resources in schools is a major issue. 


\section{(g) Lack of adequate instructional material}

A large majority of the respondents responded that insufficient instructional materials were hindering learning along with out of date approaches arising from this:

We specially focus grade 3. At this level students need rapid growth and want more and more knowledge. Some PSTs shirk work and the students idealize their teacher at this level but their teachers' traditional attitude affects their future life badly [R8].

Schools face shortage of teaching staff, oversize classes, lack of adequate classrooms, and lack of resources in these rooms.

\section{(h) Multi grade teaching}

A few respondents responded that multi-grade teaching made teaching very difficult:

Planning of lessons remains difficult because it is not possible for a teacher to prepare dozens of lessons in a day and deliver them properly [R2].

Also, one more said:

Single teacher schools are the challenging task for the DTEs due to single teacher nothing can be improved. [R8]

However, responses indicated that they felt that District Teachers Educators were making a difference.

The findings can be summarised (figure 3):

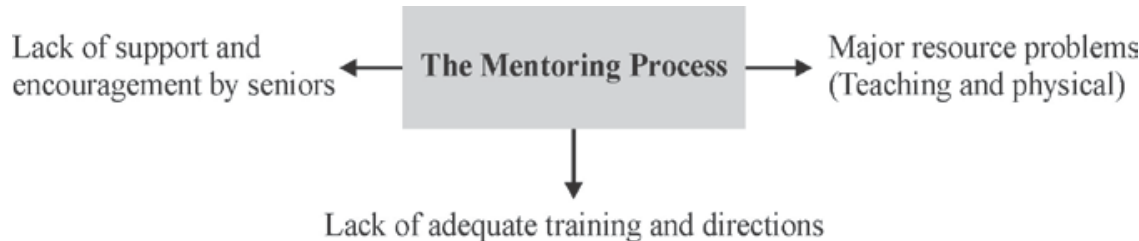

Figure 3. Mentoring Issues

\section{(3) Professional Development Days}

The following issues were observed in the data:

(a) No specific venue for professional development days

The majority of District Teachers Educators noted the lack of suitable accommodation:

There should be fully equipped separate hall for PD Day activities where they may plan according to their professional development training. [R2] 


\section{(b) Improper seating arrangement}

The majority of District Teachers Educators noted the demoralizing effect of the lack of suitable arrangements for participants:

Three seated desk benches are often used for seating during PD Day. It appears to be devaluing the teachers [R11].

Seating arrangements matter a lot for the teachers. They are not facilitated with proper sitting facility. This is because, cluster centers are not well facilitated by the high ups. [R9]

Lack of funds brings lack of facilities and undermines the value place on such days.

\section{(c) Attendance and Participation}

Half of the District Teachers Educators were of the opinion that majority of the teachers were not involved in professional development day activities.

Unfortunately, all teacher educators do not get opportunities to attend professional development courses [R1].

Most of the District Teachers Educators noted poor attendance despite instructions to attend it.

Attendance at PD Day remains less. They present lame excuses to get rid of $P D$ Day [R5].

Part of the reason is that Heads are unable to release their staff to attend.

\section{(d) Abuse of powers}

More than one third of the respondents mentioned that abuse of powers is one of the main problems:

Some officers of education department provide extra favour to some PSTs that derive the PD Day process to failure. It causes the exploitation among other PSTs [R12].

The findings can be summarised (figure 4):

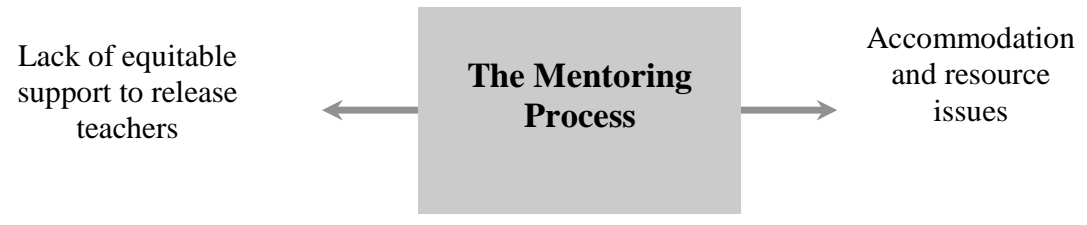

Figure 4. Professional Day Issues 


\section{(4) Head-teacher Meetings}

They all noted that the role of the head-teacher is vital and important in the whole process. If the head is attentive and interested in the whole process he/she can bring about great changes in his/her institute. The following issues were observed in the data:

\section{(a) Lack of awareness of continuing professional development}

Many respondents noted that most of the heads were unaware of continuing professional development:

They cannot understand the problems of DTEs; the conduct of Head meeting is just a formality for them [R13].

\section{(b) Untrained Head Teachers}

Many of the District Teachers Educators stated that the head teachers have not been provided training for their work in headship:

Their professional training should be made compulsory to get good results regarding CPD.[R12]

Moreover, another view is:

The DTEs face a lot of problems at the high school level, because the head of the high school is senior in status by them. The high school head takes it personal disrespected to be checked by the person who is junior to him / her in scale and status.

\section{(c) Non authoritative transfer of duties}

More than one third of District Teachers Educators mentioned that some feeder school head teachers do not attend head-teacher meeting personally and send their Representative to the meetings:

It leaves bad impact on performance of feeder school teachers due to improper conveyance of information that was provided during CTSC Head meeting [R7].

\section{(d) Non implementation of instructions}

The majority of the respondents stated that most of the teachers as well as head teachers do not follow the instructions given by higher authorities:

Sometimes head teacher meeting is just to show the presence of feeder school head teachers and put the signatures on attendance register for checking of DTEs visit by CTSC head [R12]. 


\section{(e) Lack of Speedy follows up}

Majority of the respondents were of the opinion that there is need of speedy follow up for the process. By observing this process, they can get more and urgent results that can strengthen the educational system.

There is lack of coordination between education department, DMO and DSD [R1]. Moreover, every month DTEs should conduct a meeting with DY. DEO with positive response and speedy follow up. [R6].

Both interview responses and questionnaire analysis showed that there seemed to be relationship between head-teacher's interest in teacher development and the way the school responded to teacher development. Lack of commitment for the head tends to stultify progress elsewhere.

The findings can be summarised (figure 5):

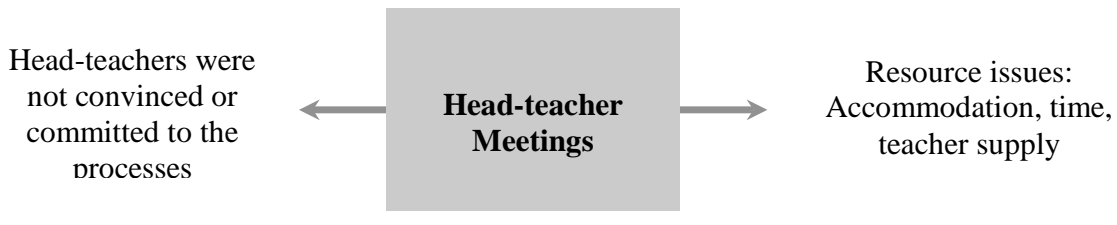

Figure 5. Professional Day Issues

\section{Discussion}

The introduction of District Teachers Educators was seen as a way to enhance the educational provision in schools in the Province of the Punjab. However, the way the roles of the District Teachers Educators have been set up relies on several assumptions. Some for these are listed:

(1) Monitoring teachers will enhance standards of student learning

(2) Test data give evidence of educational success

(3) Competition is the best way to enhance standards

(4) Reform is to be seen in terms of test performance, gathered with integrity.

(5) Mentoring by someone from outside the school but working within the schools is the best way to support teachers

Some of these are open to challenge on the basis of numerous studies throughout the world.

Looking at (1), the connection between teaching strategies and student learning is not nearly as straightforward as might be implied. Of 
course, every student is well aware of occasions when they have been taught by a gifted teacher but defining what is meant by even a 'good' teacher is not easy. Indeed, there is no direct connection between teaching strategy and levels of understanding; the review by Kirschner et al. (2006) offers a serious challenge to much careless thought. In simple terms, there is no evidence that monitoring improves student learning and it suggests that teacher's confidence and morale are undermined by the process (Horn and Wilburn, 2013).

The problem with (2) is that written tests can only measure a very narrow range of skills. Evidence shows very clearly that the main skill rewarded in such tests is the ability to recall or recognize (Almadaniet al, 2014). Understanding is often neglected while thinking skills are largely ignored. Practical skills and learning skills are rarely rewarded in any way. Again, much research shows the weakness of depending on externally set testing, in any form, to be a genuine measure of student performance (Horn\& Wilburn, 2013). There is a belief that competition 'drives up' standard. The evidence for this is simply not there. It may or may actually deflate standards (Stobart, 2008). Popham (1999) addresses this issue and draws together the evidence to show the problems.

However, there is extensive evidence to show the value of mentoring and keeping this within the schools and being conducted by those with teaching experience is sensible. Nonetheless, the gathered evidence suggests that head-teachers are not convinced in every case.

The problems identified by the interviews and open-ended questionnaires can be summarised (figure 6).

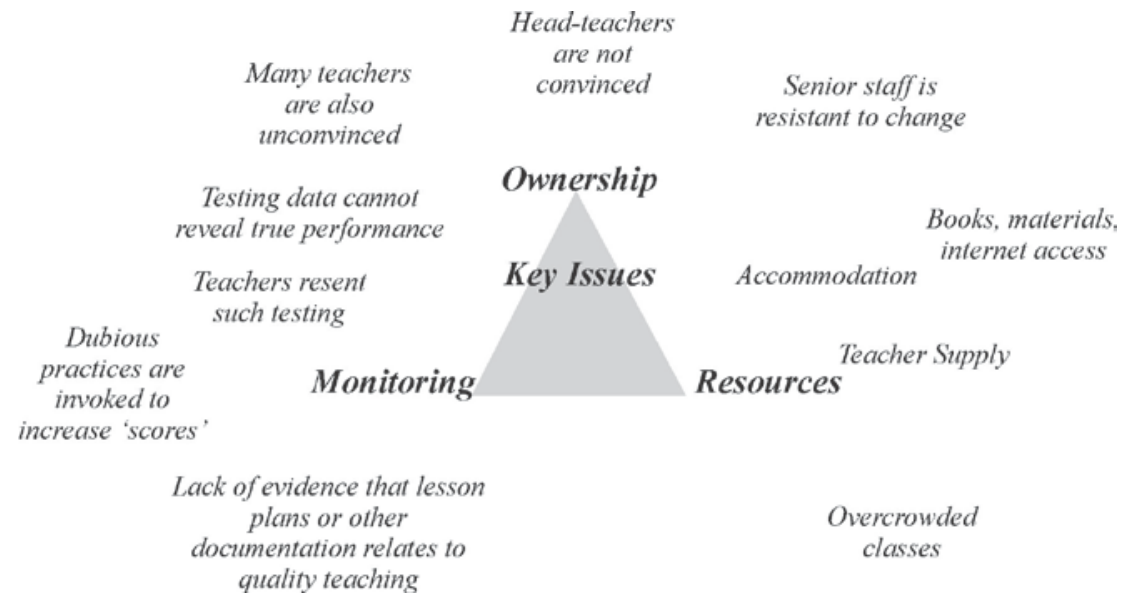

Figure 6. Summary of Issues 
From the perspective of teachers and head-teachers, they seem to see an imposition of a monitoring and support structure that does not convince them. Faced with overcrowding, teacher supply problems, problems relating to lack of written and computer resources, a group of experienced teachers have been removed from the teaching force and appointed as District Teachers Educators. The aims may be entirely to be supported but experienced head-teachers and teachers do not seem to be convinced.

In some ways, it comes back to the fundamental issue of quality assurance and how it is to be seen. Is quality assurance to be seen primarily as monitoring and accountability or as support and improvement? The two are very often in conflict (Reid, 2009):

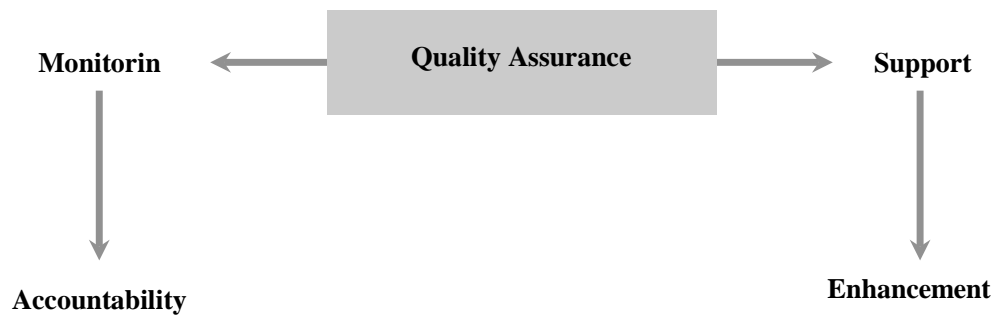

Figure 7. Accountability or Enhancement

The models often adopted in education were taken from the world of business and industry. Here there is a definable product and the efficiency of its production can be measured quantitatively. This is simply not true in the field of education. The product is an educated student but what that means will vary enormously from student to student: there is no standard 'product'. Test data are simply not a measure of quality at all. Davis et al. (2015) have drawn together the evidence and have exposed the complete fallacy of relying on test data to give a measure of schools or teacher performance. This has drawn from numerous studies, all pointing to the same broad conclusion.

Although not stated by the District Teachers Educators, the way accountability is conceptualized is almost certainly invalid. Many of the teachers and head-teachers are probably subconsciously aware of this. Added to that, it places extra work burdens on teachers and, because the test data is used inappropriately as evidence of success, they are understandably resentful at times and quite prepared to resort to all kinds of unethical behaviour in an attempt to avoid a procedure which is not fit for purpose. 


\section{Conclusions}

It is obvious that all changes in professional working practice must be 'owned' by all involved. There is, therefore, a major task to conduct dialogues with the head-teachers and teachers of the school to discuss issues relating to quality, support, resource provision. Changes will never be embraced unless all those involved are convinced that the changes are valuable and cost-effective.

The evidence from the research literature shows unequivocally that combining monitoring with enhancement is not sustainable while trying to measure the 'success' of education by means of student tests or by monitoring written documents offering invalid measures of progress. If test data are used as indicators of 'educational success' or teacher skills, teachers will find all kinds of way to circumvent the system and the evidence from numerous countries has revealed the ingenuity of teachers in finding ways to generate better test results while studies have shown that the actual standard of education has actually fallen (Davis et al., 2015).

What the interviews and questionnaires reveal is that the District Teachers Educators are working under almost impractical situations. Combining the role where they offer support, training and advice with the role where they are monitoring teachers generates an inevitable conflict and this needs resolved. The evidence suggests that their time would be better spent in the supportive-enhancement role, leaving the monitoring role aside. They are in a wonderful position to take time to read, collate evidence, form the wide range of international research findings and, from this, to offer teachers new insights and challenges that will take education in the Punjab forward.

\section{REFERENCES}

Akker, J., \& Van, D. (1998). The science curriculum: Between ideals and outcomes. In B. Fraser \& K. Tobin (Eds.), international handbook of science education. Dordrecht: Kluwer Academic Publishers, 421-447.

Almadani, K., Reid, N., \& Rodrigues, S. (2012). What examinations test, Problems of Education in the 21st century, 1(1), 6-19.

Becker, H. S., Geer, B., Hughes, E. C., \& Strauss, A. L. (1961). Boys in white: Student culture in medical school. Chicago: University of Chicago Press.

Blair, M. et. (1998). Making the Difference: Teaching and Learning, Strategies in Successful Multi-ethnic Schools, DfEE Research Report 59. London: HMSO. 
Boredom, L., Defrayed, S., Baker, A. C., \& Kolb, D. (2010). Enhancing deep learning: lessons from the introduction of learning teams in management education in France. Journal of Management Education. 35 (3), 324-350.

Borg, W. R., \& Gall, M. D. (1989). Educational research: An introduction (5th ed.). New York, NY: Longman. ISBN: 0-801-0334-6 [LB1028.B6 1989].

Bowe, C., \& Evans, M. (2005). Investigation into the effectiveness of a mentoring program an action research project.

Christine, T. (2005). Performance information in the budget process: results of the OECD 2005 questionnaire. OECD Journal on Budgeting, 5(2), 87.

Cochran-Smith, M., \& Fries, K. (2005). The AERA panel on research and teacher education: Context and goals. Studying teacher education. The report of the AERA panel on research and teacher education, 37-68.

Davis, A., Winch, C., \& Lunn, G. (2015). Educational assessment on trial. London: Bloomsbury.

Fletcher, L. and Brundrett, M. (2005). Leaders on leadership: the impressions of primary school head teachers and subject leaders. School Leadership and Management, 25(1), 59-75.

Fullan, M. (1995). Professional Development in Education: New Paradigms and Practices. In Guskey, T. A review of literature on professional development for experienced teachers, New York: Teachers College Press, 44.

Gable, E. \& Burns, M. (2005). Using technology to train teachers [online]. Retrieved on 26 September 2015 from http://www.infodev.org/en/Publication.13.html

Gall, M. D., Renchler, R. S. et al. (1985). Effective staff development for teachers: A research-based model. University of Oregon: College of Education, Government of Punjab (2010). District Teacher Educators. Lahore.

Hammerness, K., Darling-Hammond, L., Bransford, J. with Berliner, D., Cochran-Smith, M., McDonald, M., \& Zeichner, K (2006). How teachers learn and develop. In Darling-Hammond, L. \& Bransford, J. (Eds.) (2005). Preparing teachers for a changing world: what teachers should learn and be able to do. Jossey-Bass.

Harris, A. (2004). Distributed Leadership and School Improvement Leading or Misleading? Educational Management Administration \& Leadership, 32(1), 11-24.

Horn, J \& Wilburn, D, (2013). The Mismeasure of Education. Charlotte, NC: Information Age Publishing.

Huberman, M. (1992). Teacher development and instructional mastery. In Hargreaves, A. \& Fullan, M. (Eds.) Understanding Teacher Development (1992). London: Cassell Villiers House. 
Joyce, B. R., Howey, K., \& Yarger, S. (1976). I.S.T.E. Report I. Palo Alto, California: Stanford Center for Research and Development in Teaching.

Joyce, B., Mueller, L., Hrycauk, M. \& Hrycauk, W. (2005). Cadres help to create competence. Journal of Staff Development, 26 (3), 44-49.

Maslin, M. L., \& Scott, K. W. (2003). The five-question method for framing a qualitative research study. The Qualitative Report, 8(3), 447-461.

Pelgrum, W. J. \& Law, N. (2003). ICT in education around the world: trends, problems and prospects. Paris: UNESCO.

Popham, W.J. (1999) Why standardized tests don't measure educational quality, Educational Leadership, 56(6), 80-15.

Reid, N. (2010). Quality assurance in higher education in pakistan: Looking to the future, Proceedings of the 3rd International Conference on Assessing Quality in Higher Education, Lahore, Pakistan, 2-11.

Richardson, V., \& Placier, P. (2001). Teacher change. In V. Richardson, Handbook of Research on Teaching, 4th ed. Washington, DC: AERA, 905-947.

Sharon L., Nichols and Berliner, D.C. (2007). High-Stakes Testing and the Corruption of America's Schools, Harvard Education Letter, 23(2), 1-2.

Stobart, Gordon (2008) Testing Times: The Uses and Abuses of Assessment, Rutledge, London, New York.

Voogt, Mooned, B., \& Vogt, J. (1998). Using networks to support the professional development of teachers. Journal of In-service Education, 24(1), 99-110.

Received on: January 30, 2015

Revised on: January 17, 2016

March 12, 2016

Accepted on: March 21, 2016 